\title{
Lepromatous Leprosy Presenting with Polyarthritis, Myositis, and Immune-complex Glomerulonephritis
}

\section{Summary}

A Pakistani man aged 19 years was admitted to a rheumatological unit in the United Kingdom with acute widespread polyarthritis accompanied by night sweats and fever. Preliminary examination suggested Reiter's disease, but further investigation showed acute glomerulonephritis with uraemia. The possibility of periarteritis nodosa, and the prominence of muscle tenderness in the legs, led to biopsies of striated muscle and skin, in both of which were changes typical of lepromatous leprosy, with many Mycobacterium leprae on Ziehl-Neelsen staining. Serum showed IgG-IgM cryoglobulinaemia without antiglobulin activity, and in the recovery phase renal biopsy showed a resolving proliferative glomerulonephritis with linear IgG and IgM immunofluorescence and granular deposits of C3. Clinical signs subsided rapidly under steroid treatment and subsequent progress on anti-leprosy drugs was uneventful. The term erythema nodosum leprosum is inadequate and misleading as a title for a common and important immune-complex reaction of lepromatous leprosy, in which numerous body systems may be involved.

\section{Introduction}

We report here the spontaneous occurrence of type 2 (Arthus, immune-complex) reaction in lepromatous leprosy, with clinical manifestations which, though transient, were nevertheless profound.

\section{Case Report}

A 19-year-old Pakistani with a completely negative medical history during four years' residence in the United Kingdom, was admitted to the rheumatological unit at Stoke Mandeville Hospital for investigation of an acute polyarthritis involving fingers, hands, elbows, knees, and ankles. In the four weeks before admission he had suffered concurrently from pleuritic-type chest pain, cough, mild conjunctivitis, night sweats, fever, and loss of weight. Once he had attended a dermatological clinic with a few septic spots on the hands and feet from which Staphylococcus aureus was cultivated and which responded completely to sodium fusidate (Fucidin ointment). Joint swelling towards the time of admission was painful, tender, and continuous. He denied sexual contact or urethral discharge and there was no history of bowel upset. Shortly before admission he had noted two minor episodes of epistaxis.

\footnotetext{
Oxford Regional Rheumatic Diseases Research Centre and Department of Pathology, Stoke Mandeville Hospital, Aylesbury, Bucks

J. M. I. IVESON, M.B., M.R.C.P., Registrar (Present address: Rheumatism Research Unit, School of Medicine, Leeds LS2 9PJ)

H. J. HARRIS, M.B., F.R.C.PATH., Consultant Pathologist

Cochrane Annexe, Slade Hospital, Oxford OX3 7JH

A. C. McDOUGALL, M.D., M.R.C.P., Research Assistant

The Bland-Sutton Institute, Middlesex Hospital, London W.1 A. J. LEATHEM, M.B., Assistant Lecturer
}

Examination showed a thin febrile man (maximum temperature $40^{\circ} \mathrm{C}$ ) with injected conjunctivae, slight periorbital oedema, and a butterfly-distribution erythema over the face. The small joints of the hands were tender, as were the muscles generally, especially in the lower limbs, and there was spindling of the fingers with diffuse swelling of the hands, so that grip was considerably diminished. The soles of the feet and heels were tender. Splenomegaly was present $(1 \mathrm{~cm})$ but there was no lymphadenopathy. On the dorsum of the left hand there was an 8-mm circular macule, hypopigmented in the centre and hyperpigmented at the periphery and anaesthetic to cotton wool and pin-prick. Between the scapulae there were some vague and unremarkable erythematous macules but the skin was otherwise normal, and neither on admission nor subsequently did he show any evidence of erythema nodosum leprosum. Ophthalmological examination confirmed the presence of bilateral conjunctivitis and also showed an anterior uveitis with considerable flare and keratitic precipitates. The cardiovascular system and respiratory system were normal.

A provisional diagnosis of Reiter's disease became rapidly untenable when it was discovered that he had splenomegaly and a blood urea of $40.8 \mathrm{mmol} / 1(246 \mathrm{mg} / 100 \mathrm{ml})$ with a normal serum potassium, blood urea having been $5.0 \mathrm{mmol} / 1(30 \mathrm{mg} / 100 \mathrm{ml})$ before admission. Investigations at this stage showed: haemoglobin $11.2 \mathrm{~g} / \mathrm{dl}$, erythrocyte sedimentation rate (E.S.R.) $56 \mathrm{~mm}$ in $1 \mathrm{~h}$, blood urea $40.8 \mathrm{mmol} / \mathrm{l}$ $(246 \mathrm{mg} / 100 \mathrm{ml})$, blood sugar $5.6 \mathrm{mmol} / 1(100 \mathrm{mg} / 100 \mathrm{ml})$, sodium $135 \mathrm{mmol} / \mathrm{l}$, potassium $4.1 \mathrm{mmol} / \mathrm{l}$, chloride $107 \mathrm{mmol} / \mathrm{l}$, bicarbonate $11.5 \mathrm{mmol} / \mathrm{l}$, serum creatinine $168 \mu \mathrm{mol} / 1 \quad(1.9 \mathrm{mg} / 100 \mathrm{ml})$, creatinine clearance $29.5 \mathrm{ml} / \mathrm{min}$, albumin $26 \mathrm{~g} / \mathrm{l}$, and globulin $42 \mathrm{~g} / \mathrm{l}$. Electrophoresis showed increased $\gamma$-globulin. Immunoglobulins one month after admission were: IgG 39 (normal 8.8-16.8) g/l, IgM $2.05(0.5-1.9) \mathrm{g} / \mathrm{l}$, and IgA $1.85(1.4-4.3) \mathrm{g} / 1$. He was positive for smooth-muscle antibodies. Urinary investigations showed: daily output (average) $2240 \mathrm{ml}$, protein $640 \mathrm{mg} / 24 \mathrm{~h}$, sugar up to $1 \%$, acetone nil, red cells $82 / \mathrm{mm}^{3}$, casts nil, pus cells $9 / \mathrm{mm}^{3}$, growth nil, sodium 59 mmol/l, potassium $38 \mathrm{mmol} / \mathrm{l}$, chloride $55 \mathrm{mmol} / \mathrm{l}$. The following investigations were also performed but the results were normal: sheep cell agglutination test, slide latex test, gonococcal fixation test, Venereal Diseases Research Laboratory test, and blood culture. Creatinine phosphokinase antinuclear factor, and mitochondrial antibodies were also normal.

The association of an acute uraemia, without oliguria, with a multisystem disorder affecting skin, eyes, muscle, and joints suggested polyarteritis nodosa with renal involvement. Treatment with prednisolone $60 \mathrm{mg}$ and chlorambucil $4 \mathrm{mg}$ was started together with $\mathrm{r} \%$ homatropine, betamethasone sodium phosphate (Betnesol) eye drops, and a high-calorie low-protein diet. To confirm the initial diagnosis, and because of the prominence of muscle tenderness, biopsies of striated muscle (left gastrocnemius) and skin (hypopigmented area on dorsum of left hand) were peformed. The dermis showed a heavy lepromatous infiltrate with a free subepidermal zone and masses of acid-fast bacilli on Ziehl-Neelsen staining in macrophages, endothelial cells, and dermal nerve filaments. Vessels in the mid-dermis and lower dermis showed evidence of a resolving vasculitis. Polymorphs were not in evidence and oedema was not significant. Gastrocnemius was heavily involved (fig. 1), with masses of foamy macrophages and bacilli between, and often invading and replacing, muscle fibres (fig. 2).

At this point the patient was started on clofazimine (Lamprene) $100 \mathrm{mg}$ three times daily. Biopsy specimens of right superficial peroneal nerve and of nasal septum taken between two and three weeks after the start of this treatment were similarly infiltrated with Mycobacterium leprae, and slit-skin smears from six different sites gave a bacterial index ${ }^{1}$ (B.I.) of $4 \cdot 1$, and a morphological index (M.I.; the percentage of solidly-staining forms on Ziehl-Neelsen staining) of 0.5 . Homogenates of biopsy specimens gave $2.0 \times 10^{8}$ acid-fast bacilli/g for nerve, with M.I. 2, and $7.5 \times 10^{7}$ acid-fast bacilli/g for muscle, with M.I. 2; a 24-hour collection of nasal mucus produced $3.0 \times 10^{5}$ in a blood-stained specimen, with M.I. zero. Lepromin test, using Mitsuda-type lepromin standardized to $1.6 \times 10^{8}$ acid-fast bacilli $/ \mathrm{ml}$, was negative.

In the recovery phase renal biopsy specimens showed a resolving acute proliferative glomerulonephritis, suggested by a mild diffuse 


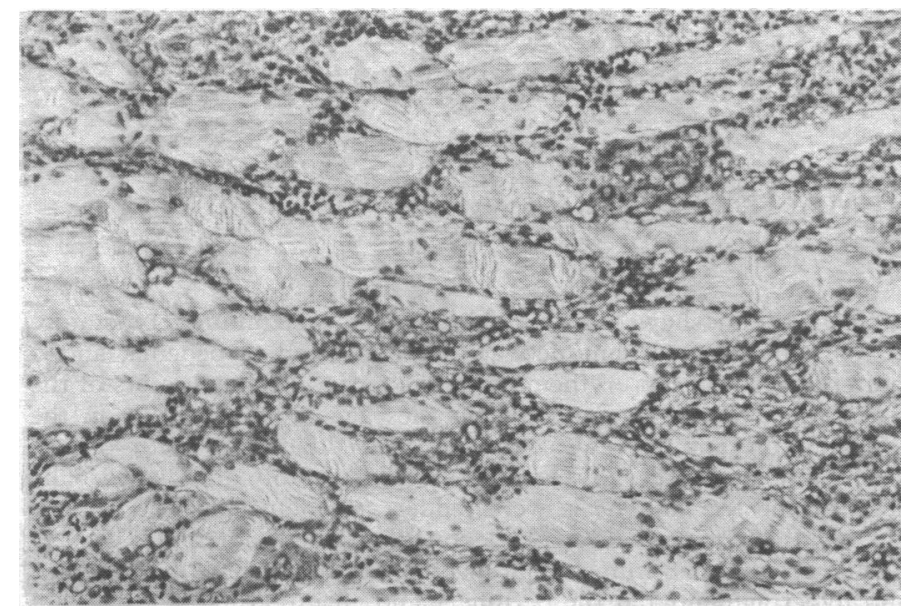

FIG. 1-Gastrocnemius: pretreatment biopsy specimen showing infiltrate of foamy Virchow cells, lymphocytes, and plasma cells separating, and in some areas replacing, muscle fibres. Mycobacterium leprae are profuse in cytoplasm of infiltrating and sarcolemmal macrophages, both singly and in globi; some of the latter show central vacuolation. (Combined Masson's trichrome and Fite-Faraco. $\times$ 156.)

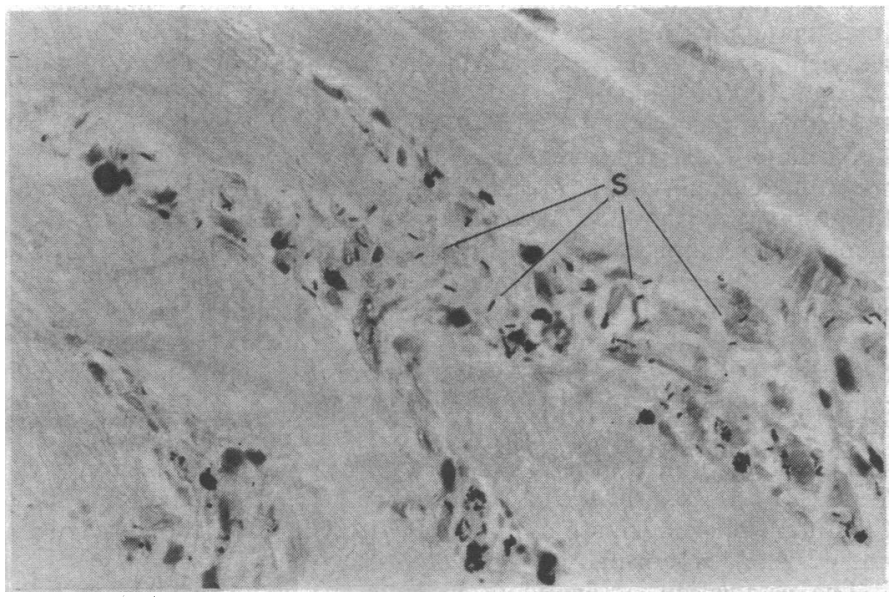

FIG. 2-Gastrocpemius: pretreatment biopsy specimen showing numerous bacilli, some of them (S) in solid-staining (and therefore presumably viable) form lie in infiltrate between fibres. (Combined Masson's trichrome and Fite-Faraco. $\times$ 625.)

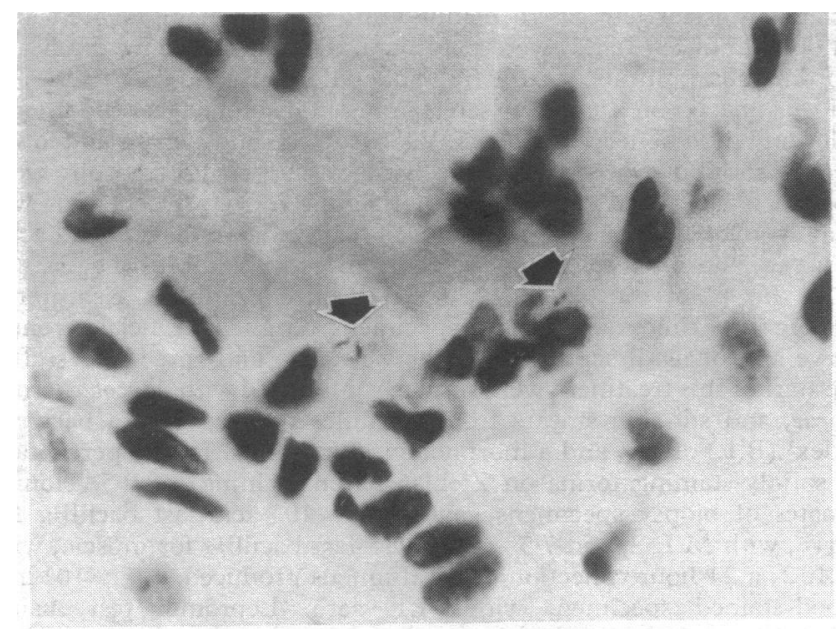

FIG. 3-Kidney: biopsy specimen taken during the recovery phase showing group of non solid-staining bacilli (arrowed) associated with juxtaglomerular apparatus. (Wade-Fite. $\times 625$.) endocapillary (predominantly mesangial) proliferation with mesangial hypertrophy and increase in tuft size involving all glomeruli. A group of bacilli were seen associated with the juxtaglomerular apparatus of one glomerulus (between the capsule and macula densa) in one section stained with Wade-Fite (fig. 3).

Renal Immunofluorescence. - There was a weak"diffuse discontinuous linear fluorescence with anti-IgG and anti-IgM and a more intense diffuse scattered granular fluorescence with anti-C3 in all glomeruli. No fixation was seen with fibrinogen. Occasional tubular casts stained intensely with anti-IgA and some tubule cytoplasm granules with anti-IgE.

Cryoglobulins.-A cryoprecipitate separated at a concentration of $20 \mathrm{mg} / \mathrm{l}$ blood (about $20 \%$ not dissolving on warming to $37 . \mathrm{C}$ ), and contained IgG and IgM, IgM forming a more intense precipitate than IgG. The cryoglobulin contained no antiglobulin activity.

The finding of ubiquitous acid-fast bacilli prompted a reassessment of peripheral nerves, and some enlargement of the right ulnar, right terminal radial at the wrist, and left lateral popliteal nerves was now evident. The whole skin surface was again checked for erythema nodosum leprosum and was found to be negative. Chlorambucil was stopped early; prednisolone was continued but gradually reduced; and rifampicin (and later dapsone) was used as the anti-leprosy drug. Within a few weeks the myalgia, arthralgia, splenomegaly, uveitis, E.S.R., and renal function rapidly and completely resolved. Bacterial indices and serial biopsies in the two years after admission showed entirely satisfactory progress.

\section{Discussion}

Though the biopsy specimen from the dorsum of the left hand might have represented a solitary (and mainly resolved) leșion of erythema nodosum leprosum, this manifestation was otherwise totally lacking in the skin of a patient whose clinical and laboratory findings pointed clearly to a spontaneous immunecomplex reaction in lepromatous leprosy.

The terminology of various reactions occurring in lepromatous and non-lepromatous forms of this disease has been summarized, ${ }^{2}{ }^{3}$ and for some years Jopling ${ }^{4}$ has made a plea for their division into type 1 (cell-mediated, resulting in a change of immunological status) and type 2 (humoral, with no effect on immunological status). Type 2 reactions are concerned with antigen, antibody, and complement and have features akin to the Arthus phenomenon and serum sickness. ${ }^{5}$ Erythema nodosum leprosum on the skin, first described by Murata, ${ }^{6}$ is a common but by no means invariable feature of type 2 reaction, as this patient shows. Indeed the absence of erythema nodosum leprosum was in striking contrast to the involvement of joints, kidneys, and eyes.

In one detailed study ${ }^{7}$ only $54.7 \%$ of 84 polar lepromatous patients developed erythema nodosum leprosum, and this "escape," often over many years of observation, is still unexplained. Equally remarkable ${ }^{8}$ is the fact that even when circulating immune-complexes are shown in lepromatous patients $^{9}$ as many as a third do not develop erythema nodosum leprosum. It has often been observed that some patients have only one, or a few, mild attacks while others may be constantly afflicted; and that in some patients the same organs are repeatedly involved while in others they change with successive attacks. As far as joint involvement in type 2 reaction is concerned the published work has been well summarized, ${ }^{10}{ }^{11}$ and in a particularly relevant report ${ }^{12}$ concomitant myositis was present in five out of 18 cases $(28 \%)$, and a notable inverse relation was recorded between the occurrence of joint and skin lesions. The heavy infiltration of striated muscle in our case was not accompanied by palpable nodules, but there were otherwise several close similarities with the patient reported by Jopling and Mehta, ${ }^{13}$ whose skin was also clinically unaffected.

Uraemia due to chronic glomerulonephritis is a major cause of death in lepromatous leprosy, ${ }^{14-16}$ and proteinuria, microscopic haematuria, cell casts, and oedema suggestive of glomerulonephritis are not unusual in reactional episodes. ${ }^{17}$ Nevertheless, leprosy has not usually been thought of as a cause of glomerulonephritis and in necropsy material ${ }^{18}$ repeated erythema nodosum 
leprosum has been suspected but not proved to be the cause of nephritic changes. Recently Drutz and Gutman have published a detailed study on the specific relation of glomerulonephritis to type 2 reaction in lepromatous leprosy, ${ }^{19}$ and our findings are in accordance with their conclusions and those of others ${ }^{20}{ }^{21}$ on the role of immune-complex deposition in glomerular basement membranes and capillary walls. The occurrence of bacilli in relation to the juxtaglomerular apparatus must be rather unusual, and though bacilli have been found in necropsy studies, and also in biopsy specimens, ${ }^{22}$ kidney parenchyma is not usually invaded in this disease. The common association of cryoglobulinaemia with lepromatous leprosy has been described, ${ }^{23}$ and our finding of IgG and IgM in both glomeruli and the cryoglobulin suggests that they share a part in the pathogenesis of this glomerulonephritis. To our knowledge there are no published data relating the incidence of proteinuria or glomerulonephritis to that of serum cryoglobulins in leprosy, though this association has often been noted in other diseases. In conclusion the inverse relation between skin and joint manifestations in this syndrome seems to be worth further investigation, as are the effects of renal involvement on the prognosis for patients with lepromatous leprosy in reaction.

We thank Dr. A. G. S. Hill, director of the Oxford Regional Rheumatism Research Unit at Stoke Mandeville Hospital, for permission to report this case and for helpful advice in preparation, and Dr. R. J. W. Rees of the National Institute for Medical Research, Mill Hill, London NW7 1AA, for data on concentrations and morphology of leprosy bacilli in biopsy specimens and nasal mucus. A. C. McDougall is supported by grants from the Medical Research Council and the British Leprosy Relief Association.

\section{References}

1 Ridley, D. S., Leprosy in Theory and Practice, ed. R. G. Cochrane and T. F. Davey, p. 620. Bristol, John Wright and Sons, 1974.

2 Jopling, W. H., Handbook of Leprosy. London, William Heinemann Medical Books, 1971.

${ }^{3}$ Bryceson, A., and Pfaltzgraff, R. E., Leprosy for Students of Medicine. Edinburgh and London, Churchill Livingstone, 1973.

4 Jopling, W. H., Leprosy Review, 1970, 41, 62.

5 Wemambu, S. N. C., et al., Lancet, 1969, 2, 933.

- Murata, M., Zeitschrift für Dermatologie und Urologie, 1912, 12, 1013.

${ }^{7}$ Pettit, J. H. S., and Waters, M. F. R., International fournal of Leprosy, $1967,35,1$.

${ }^{8}$ Godal, T., et al., Bulletin de l'Institut Pasteur, 1974, 72, 273.

9 Moran, C. J., et al., Lancet, 1972, 2, 572.

10 Karat, A. B. A., et al., British Medical fournal, 1967, 3, 770.

11 Manigrand, G., et al., Semaine des Hôpitaux de Paris, 1969, 45, 543.

12 Ramu, G., and Balakrishnan, S., Leprosy in India, 1968, 40, 62.

13 Jopling, W. H., and Mehta, H. D., Leprosy Review, 1972, 43, 39.

14 Brusco, C. M., and Masanti, J. G., International Fournal of Leprosy, 1963, 31, 14.

${ }^{15}$ Kean, B. H., and Childress, M. E., International fournal of Leprosy, 1942, 10,51 .

16 Granells, M., International fournal of Leprosy, 1968, 36, 645.

17 World Health Organization, Bulletin of the World Health Organization, $1970,43,879$.

18 Desikan, K. V., and Job, C. K., International fournal of Leprosy, 1968, 36, 32 .

19 Drutz, D. J., and Gutman, R. A., American fournal of Tropical Medicine and Hygiene, 1973, 22, 496.

20 Tin Shwe, Leprosy Review, 1971, 42, 282.

21 Bullock, W. E., Callerame, M. L., and Panner, B. J., American fournal of Tropical Medicine and Hygiene, 1974, 23, 81.

22 Hill, G. J., Leprosy in Five Young Men. Colorado, Colorado Associated University Press, 1970.

${ }^{23}$ Bonomo, L., and Dammacco, F., Clinical and Experimental Immunology, $1971,9,175$

\title{
Erythropoietic Uroporphyria of Gunther First Presenting at 58 Years with Positive Family Studies
}

\author{
R. W. PAIN \\ F. W. WELCH, \\ A. J. WOODROFFE, \\ D. A. HANDLEY, \\ W. H. LOCKWOOD
}

British Medical fournal, 1975, 3, 621-623

\section{Introduction}

After the demonstration of defects in both bone marrow and liver in erythropoietic protoporphyria ${ }^{1}$ three major divisions of the porphyrias have been described-namely, the erythropoietic, erythrohepatic, and hepatic types. ${ }^{2}$ The erythropoietic group is the rarest of the porphyrias. Only two cases of erythropoietic coproporphyria and 70 authentic cases of congenital erythropoietic uroporphyria (Gunther's disease) have been recorded. ${ }^{3}$ In 1962 Goldberg et al. ${ }^{4}$ wrote of the latter condition, "all cases in whom a definitive statement was made regarding age of onset presented in childhood and no patient has survived to middle age." In 1965, however, a Bantu man was reported whose first manifestations occurred when he was $55 .^{5}$ Of all recorded cases of Gunther's disease, the man we describe here is the first in Australia, the ninth with associated thrombocytopenia, and the oldest at initial presentation.

\section{Australia 5000}

Institute of Medical and Veterinary Science, Adelaide, South

R. W. PAIN, M.B., F.R.C.P.A., Clinical Chemist (Medical), Division of Clinical Chemistry

D. A. HANDLEY, F.R.A.C.P., M.R.C.PATH., Assistant Director of Haematology, Division of Haematology

Florey House, North Adelaide, South Australia 5006

F. W. WELCH, M.B., M.A.C.D., Consultant Dermatologist

Royal Adelaide Hospital, Adelaide, South Australia 5000

A. J. WOODROFFE, M.B., F.R.A.C.P., Senior Medical Registrar (Present address: Renal Unit, Queen Elizabeth Hospital, Woodville, South Australia 5011)

Institute of Medical Research, Royal North Shore Hospital, New South Wales 2065

W. H. LOCKWOOD, B.SC., Research Fellow of the National Health and Medical Research Council of Australia

\section{Case Report, Methods and Results}

The patient, an Australian man with British forebears, presented to a dermatological outpatient clinic in March 1965 aged 58 years. He had a three-month history of recurrent blistering of the skin of the face, scalp, and hands on exposure to the sun, plus intermittent red or dark urine. He had never been thus afflicted before. He admitted to a moderate daily intake of alcohol, but was not on any medication. There was no family history compatible with porphyria. He was married with no children. Physical examination showed a hairy man with blistering of the face, scalp, and hands. Mild facial hypertrichosis 